Research Article

\title{
Assessment of competency of medical students in community medicine
}

\author{
Jeevithan Shunmugam*, Dhanasekar Gurupatham
}

Department of Community Medicine, Annapporana Medical College \& Hospital, Salem, Tamil Nadu, India

Received: 05 November 2015

Revised: 13 November 2015

Accepted: 23 November 2015

\section{*Correspondence:}

Dr. Jeevithan Shunmugam,

E-mail: dr.jeevithan@gmail.com

Copyright: (C) the author(s), publisher and licensee Medip Academy. This is an open-access article distributed under the terms of the Creative Commons Attribution Non-Commercial License, which permits unrestricted non-commercial

\begin{abstract}
Background: Competence is the ability to perform a specific task in a manner that yields desirable outcomes. This implies the ability to apply knowledge and skills successfully to new situations as well as to familiar tasks for which prescribed standards exist. The current examination pattern is designed much to test the knowledge of the students and not the skill.

Methods: A cross sectional study was designed to assess the knowledge and skill acquired by the students during the course of their study in Community Medicine, for different batches of students during various semesters, based on the MCI guidelines.

Results: The score ranged from 0 to $67 \%$ in knowledge component and 3.49 to $13.29 \%$ in skill component.

Conclusions: The mastery of practical skill and problem solving ability are important equally. So it is essential to move away from the knowledge dominated examinations to more skill oriented examinations.
\end{abstract}

Keywords: Competency, Knowledge, Skill, Assessment

\section{INTRODUCTION}

Competence is the ability to perform a specific task in a manner that yields desirable outcomes. This implies the ability to apply knowledge, skills and abilities successfully to new situations as well as to familiar tasks for which prescribed standards exist. Health workers acquire competence over time. ${ }^{1}$ It can also be defined as the habitual and judicious use of communication, knowledge, technical skills, clinical reasoning, emotions, values and reflection in daily practice for the benefit of the individuals and communities being served. ${ }^{2}$

A student's clinical reasoning may appear to be competent in areas in which his or her base of knowledge is well organized and accessible but may appear to be much less competent in unfamiliar territory. ${ }^{2}$

Medical teaching has developed steeply in the past decade and had many facets being introduced to its portfolio. Assessment is one such area which was scrutinized for further development. Educational experts are of the opinion that assessment needs to be aligned with the course objectives as well as the intended outcomes and it should not only be a hurdle to complete the course, but also a way of receiving feedback and further improve the student's competencies. ${ }^{3}$

While the graduates generally possess reasonably sound knowledge of medical science, they are often found deficient in the performance of clinical skills and problem-solving which form the core of clinical competence.

In the traditional curricula, the stress has been laid on the acquisition of knowledge as against the development of skills. More attention needs to be given to the development of various skills, viz., problem-solving skills, psychomotor or performance skills, attitudinal and communication skills. 
It is a well-known fact that the way students learn is largely driven by the way they are assessed. Assessment system in medical education, therefore largely determines its product. Though the mastery of practical skills and problem solving ability are important, their assessment generally leaves a lot to be desired. It is essential to move away from the knowledge dominated examinations to more skill oriented examinations. The assessment should predominantly be based on the core curriculum and should be criterion referenced. ${ }^{4}$ Studies have shown that there is a great need for training in the aspect of doctorpatient relationship. ${ }^{5}$

\section{Assessment}

Assessment is the process of gathering and discussing information from multiple and diverse sources in order to develop a deep understanding of what students know, understand and can do with their knowledge as a result of their educational experiences; the process culminates when assessment results are used to improve subsequent learning. ${ }^{6}$

To correct this problem, several new methods of assessment have been developed and implemented over the past 50 years. These new methods have focused on clinical skills (taking a history from a patient and performing a physical examination), communication skills, procedural skills and professionalism. ${ }^{7}$

The aim and objectives of the study was to assess the competence of medical students across their course on select professional skills and to analyse the level of competence achieved with different phases in their curriculum.

\section{METHODS}

A cross sectional study to find out the professional competency achieved at the end of their course among the medical undergraduates of Rajah Muthiah Medical College was conducted for a period of 13 months from February 2009 to February 2010.

A list of selected competencies to be achieved as per the norms set by Medical council of India (1997 revised curriculum) was prepared which included three domains namely Cognitive, Affective and Psychomotor.

This cross sectional study covered first and second MBBS students, during their community medicine postings in different spells. The study population in different phases of their course is presented as a chart below.

The following few assumptions were made before the study was started

1. The competency achieved at the end of the medical curriculum is the result of cumulative and phased inputs which includes tutoring (classroom teaching), observation, practical exercises, self-learning and reflection and internship training. Otherwise the end product is the result of inputs by different departments and different teaching programmes in different phases of the course duration.

2. Even though the study was a cross sectional study, data was collected from different batches of students starting from the first MBBS to internees and it is assumed that the input given to the students is uniform for all the students across the batches that comprised our population.

Taking into consideration the practical difficulties in assessing all the competencies prescribed by MCI, a list of core competencies to be achieved at the end of the curriculum in community medicine / public health were chosen for evaluation.

The list of competencies included in our study is as follows.

\section{Students while completing community medicine must:}

1. Outline roles of individuals, family and community and socio cultural milieu in health and disease.

2. Identify the environmental and occupational hazards and their control.

3. Describe the importance of water and sanitation in human health.

4. Diagnose and manage common nutritional problems.

5. Diagnose and manage maternal and child health problems.

6. Collect, analyze, interpret and present simple community and hospital based data.

7. Diagnose and manage common health problems and emergencies at individual, family and community levels keeping in mind the existing health care resources and in the context of prevailing socio cultural beliefs.

During first MBBS, students are oriented to the community. They are given introduction and exposure to the rural set up and environment, introduction to public health, concept of health and disease, community diagnosis and health care delivery system, family survey, collection of data on health, environmental and socio economic profile / dimensions. Students are given an opportunity to directly observe the actual situation where families live and work. During this exposure data collection skill, data presentation, analysis and interpretation are taught. It is also assumed that attitude changes do happen during the exposure i.e., willingness to understand the problem in the context of socio cultural milieu.

During the third term, students are given introduction to research methodology and measures of epidemiology. Team work is stressed. The students are divided into different batches and they are guided to formulate a 
hypothesis, select a suitable epidemiological design of study and interpret the findings with the help of staff members. This is done to enable the students to learn basic concepts of epidemiology.

Fourth term students are taught essentials of environment, nutrition, family planning, vaccines, calculation of amount of bleaching powder needed for disinfection of well, waste management, entomology, effects of overcrowding in a house and housing conditions. They are taken to field and allotted individual houses for a week and will be assisted in collection of environmental data such as water source assessment, soakage pit construction, searching for breeding places (example insects), measurement of site area and built up area. They are trained to draw the sketch of house and identify the shortcomings and comparing with the standard, to measure overcrowding, to collect data regarding water supply, sanitary latrine, solid and liquid waste disposal. Students are also taught to assess the economic status of the family, to assess the health knowledge of the family, to calculate the diet and nutritional status of the family members and to find out the deficiencies and educate them regarding nutrition and personal hygiene and home economics, to collect child health record, to collect data and keep maternity records including prenatal, intranatal, postnatal, family planning and family problems and needs and to assess the influence of social factors affecting health. During this phase, skill of clinical reasoning, problem solving ability, examination of family members in the allotted households and maintenance of positive health of family members in different age groups are developed.

Pretested structured questionnaire was prepared separately for the students of first MBBS, third term and fourth term. They were administered to them without any prior information. The questions were designed to assess the knowledge and skills of the students.

\section{Sampling}

Entire batch of first year students who have been posted in the department of Community Medicine, RMMC and who were present on the last day of their posting.

\section{Study setting}

The students were assessed in the department of Community Medicine during their regular posting as a routine observation without prior information.

\section{Study tool}

Students: Observation and pretested structured questionnaire.

\section{Statistical analysis}

The data collected from students was analysed separately for each group by simple proportions, ratio.

\section{RESULTS}

Table 1: Sex wise distribution of students.

\begin{tabular}{|c|c|c|c|}
\hline \multirow{2}{*}{$\begin{array}{l}\text { Year of } \\
\text { study }\end{array}$} & \multicolumn{2}{|l|}{ Gender } & \multirow{2}{*}{ Total (\%) } \\
\hline & Male (\%) & Female (\%) & \\
\hline First year & $67(46.85)$ & $76(53.15)$ & $143(100 \%)$ \\
\hline Third term & $12(31.57)$ & $26(68.43)$ & $38(100 \%)$ \\
\hline Fourth term & $14(38.88)$ & $22(61.12)$ & $36(100 \%)$ \\
\hline
\end{tabular}

Table 1 shows that the proportion of female students are more in all the three groups. The difference is very high in third and fourth terms, since pass percentage is higher among girls.

Table 2: Assessment of knowledge of students in different phases in different cohorts.

\begin{tabular}{|ll|}
\hline Question & $\begin{array}{l}\text { Proportion } \\
\text { answered } \\
\text { correctly (\%) }\end{array}$ \\
\hline List out vaccines & 56.64 \\
\hline $\begin{array}{l}\text { Describe various socio economic } \\
\text { scales used }\end{array}$ & 25.18 \\
\hline Explain concept of ice berg & 24.47 \\
\hline $\begin{array}{l}\text { Outline infrastructure of health } \\
\text { care delivery system }\end{array}$ & 63.64 \\
\hline $\begin{array}{l}\text { Explain concept of eligible and } \\
\text { target couple }\end{array}$ & 9.09 \\
\hline $\begin{array}{l}\text { Assessment of common health } \\
\text { problems among elderly }\end{array}$ & 66.67 \\
\hline $\begin{array}{l}\text { Interpretation of blood pressure, } \\
\text { GTT, Hb1Ac }\end{array}$ & 0 \\
\hline
\end{tabular}

In the assessment of selected competencies on knowledge over the period of three years in their curriculum, it is obvious that knowledge acquired in certain areas such as health care delivery system, vaccines and assessment of common health problems is significantly higher and satisfactory compared to knowledge scored in socio economic scales and target couple and eligible couple, which is a part of maternal and child health and family welfare as shown in the Table 2.

Students have scored very badly in the application of knowledge i.e. interpretation of systolic and diastolic blood pressure and cut off value for GTT/Hb1Ac (Table $2)$.

Compared to gain in knowledge, the proportion of students who have attained proficiency in skill is poor in all the skills assessed as shown in Table III. Attainment 
of desirable skill at its maximum is less than $15 \%$ of students in general (Table 3).

Table 3: Assessment of skill of students in different phases in different cohorts.

\begin{tabular}{|ll|}
\hline Question & $\begin{array}{l}\text { Proportion done } \\
\text { correctly }(\%)\end{array}$ \\
\hline Calculate sex ratio & 12.59 \\
\hline $\begin{array}{l}\text { Calculate socio economic } \\
\text { scale }\end{array}$ & 13.29 \\
\hline $\begin{array}{l}\text { Differentiate impairment, } \\
\text { handicap \& disability }\end{array}$ & 8.39 \\
\hline $\begin{array}{l}\text { Differentiate target } \\
\text { couple from eligible } \\
\text { couple }\end{array}$ & 3.49 \\
\hline $\begin{array}{l}\text { Interpretation of } \\
\text { overcrowding }\end{array}$ & 8.33 \\
\hline $\begin{array}{l}\text { Interpretation of } \\
\text { environmental status }\end{array}$ & 9.45 \\
\hline $\begin{array}{l}\text { Interpretation of diet } \\
\text { (requirement) }\end{array}$ & 5.56 \\
\hline
\end{tabular}

\section{DISCUSSION}

Competency in health care is the capability to perform acceptably those duties directly related to patient care. Competency is defined in the context of particular knowledge, skills and abilities. Skill is one of the expected functions of knowledge.

Knowledge component and cognitive skill among students was measured immediately after the completion of their respective postings. Only selected knowledge questions and cognitive skill were assessed.

As far as the knowledge component is concerned the score ranged from $0 \%$ to $66.67 \%$. It is observed that in recall type of questions, correct answers were received compared to higher level of knowledge, for example analytical, application and judgmental. The score obtained for the interpretation of the common investigation like blood pressure/Hb1Ac/GTT is poor as compared to recall knowledge (e.g. listing out of the vaccines). Knowledge required recalling the list of vaccines is different from the knowledge required for interpretation of GTT/Hb1Ac/Blood pressure.

Though knowledge level among female students is comparatively better, the difference was not tested for statistical significance since the number of students in male/female category was small.

The study revealed that in certain areas knowledge was better e.g., like in outlining the infrastructure of health care delivery system, assessment of common health problems among elderly, listing out vaccines compared to interpretation of blood pressure, GTT, Hb1Ac, calculation of socio economic status etc., which may be explained by mastery over different levels of knowledge already discussed or exposure to a particular topic.

The cognitive skill which is basically, the applied knowledge to carry out the specific function was tested on selected areas such as calculation of sex ratio, interpretation of environmental conditions, interpretation of diet etc., They were assessed by observation and simple classroom assignment. Compared to knowledge gained, the level of competence achieved in cognitive skill is relatively poor (ranges between 3.49 and 13.29). Attainment of desirable skill at its maximum is less than $15 \%$ of students in general.

The medical evaluation or examination system, what we have today does not have structured assessment for attitude learning. Right kind of attitude is very important. The attitude among students was observed during field activities. Since there is no formal, uniform and objective assessment, the attitude component for students is not included for analysis.

\section{Limitations}

1. The study was done in a private medical college set up so the results cannot be generalizable to the undergraduate medical students, in other institutions like state/central Government institutes.

2. Students have the practice of studying just before the university examinations and the assessment of knowledge was carried out at the end of the postings in the present study. Hence the results obtained need not be the same or true at the end of the course especially in knowledge domain.

3. Many assumptions were made in this cross sectional study, about the input, nature of students, etc. One of the assumptions is that the input/methodology of teaching is same/remains unchanged for different batches. It may be correct or it may not be.

\section{CONCLUSION}

Though the mastery of practical skills and problem solving ability are important, their assessment generally leaves a lot to be desired. It is essential to move away from the knowledge dominated examinations to more skill oriented examinations. There is a need to rationalize the examination system by giving due emphasis on the 'formative' or internal assessment, introduction of logbooks and supplementing the traditional long/short case examination with more valid and reliable instruments for assessment of clinical skills like objective structured clinical examination (OSCE) . The assessment should predominantly be based on the core curriculum and should be criterion referenced, i.e., the performance of students is assessed against a standard criterion and not just in comparison to others. In practice, most of the examinations in medicine are norm-referenced or peerreferenced because no clear criteria are laid down beforehand. A formal assessment at the end of internship 
can ensure proper utilization of this period for development of skills.

Funding: No funding sources

Conflict of interest: None declared

Ethical approval: The study was approved by the Institutional Ethics Committee

\section{REFERENCES}

1. Kak N, Burkhalter B, Cooper M. Measuring the Competence of Healthcare Providers, Quality Assurance project, USAID. 2001; 2(1):1-3.

2. Epstein RM. Assessment in Medical Education. NEJM. 2007;356:387-96.

3. Siribaddana P. Medical education: Assessment methods in medical teaching, Helium. Cited 2010 May $31 . \quad$ Available from: http://www.helium.com/items/1654622 assessment-methods-in-medical-education.
4. Sood R, Adkoli BV. Medical Education in India Problems and Prospects. Indian Academy of Clinical Medicine. 2000;1(3):210-12.

5. Manickam LSS, Sathyanarayana Rao TS. Undergraduate medical education: Psychological perspectives from India. Indian Journal of Psychiatry. 2007;49(3):175-8.

6. Yasmeen G. Importance of Assessment. (Internet). 2006 Feb 16. Cited 2010 May 25. Available from: http://DAWN. Com/importance of assessment.

7. Norcini JJ, McKinley DW. Assessment methods in medical education. Teaching and Teacher Education. 2007;23:239-50.

Cite this article as: Shunmugam J, Gurupatham D. Assessment of competency of medical students in community medicine. Int J Community Med Public Health 2016;3:99-103. 